Running head: LEADERSHIP AS AN EMERGENT GROUP PROCESS

Leadership as an Emergent Group Process: A Social Network Study of Personality, Leadership, and Followership

\title{
Cécile Emery
}

Thomas S. Calvard

Meghan E. Pierce 


\title{
Leadership as an Emergent Group Process:
}

\section{A Social Network Study of Personality, Leadership, and Followership}

\begin{abstract}
A longitudinal study was conducted on the social network of a leaderless group to explore how Big Five personality traits affect leadership emergence, in the form of receiver ties (being nominated as a leader), sender ties (nominating others as leaders), and similarity effects (nominating similar/different others as leaders). Forty one students on a three-month study aboard program participated in intensive group work, and their perceptions of emergent task-and relationship-oriented leadership within these groups were assessed three times across the life cycle of the group. Results indicated that individuals scoring higher on extraversion, openness to experience, and conscientiousness were nominated more as task-and relationship-oriented leaders, whereas those who were more agreeable were more likely to emerge as relationshiporiented leaders. In terms of emergent followership, group members who were more agreeable and neurotic (and less open to experience) were less likely to follow relationship-oriented leaders, whereas more conscientious individuals were more likely to follow task-oriented leaders. With respect to the effects of complementarity and similarity, both task- and relationship-oriented leader nominations were based on dissimilar levels of agre eableness between leaders and followers, while nominated relationship-based leaders tended to have similar levels of openness to experience to followers. Implications of these results are discussed.
\end{abstract} Keywords: Emergent leadership; Social network analysis; Big Five; Personality 
Traditionally, leadership theory and research has been predominantly leader-centered, driven by the search for the profile of the good leader (for a review, see Judge, Piccolo \& Kosalka, 2009). More recently, some researchers have adopted a follower-centered approach and argued that without followers there can be no leadership, and that followers play a key role in constructing and endorsing the leader (Meindhl, 1995; Schyns \& Felfe, 2006). Although both of these research streams have provided major insights about both leaders and followers, by largely adopting an individualistic approach they have failed to capture an essential quality of leadership. Namely, that leadership (and followership) is a dynamic process that is played out in a group context, shaped by the interactions of multiple interdependent actors (Derue \& Ashford, 2010; Uhl-Bien, 2006).

The current article attempts to address this important issue by simultaneously examining emergent leadership and followership as an interactive group process. More specifically, the aim of this study was to examine the extent to which group members' personality traits (as measured by the "Big Five") predict the emergence of leaders and followers in the context of leaderless or self-managing groups. Although no formal leaders (or followers) are appointed in such groups, there is an implication that one or potentially several leaders will dynamically emerge, as recognized by other groups members, and this is how emergent leadership is typically defined (Taggar, Hackett, \& Saha, 1999). In parallel, followers naturally emerge by group members attributing a leadership role to others in the group, and this is how we defined emergent followership. Thus, leaderless groups are an ideal context for assessing group members' 
perceptions of emergent leadership and followership as they unfold over the life cycle of the group.

The present investigation extended previous research on leadership and followership in a number of important ways. First, we adopted a more fine-grained approach to conceptualizing our key dependent variable, leadership emergence, by distinguishing between two theoretically important kinds of leadership behavior: task- and relationship-oriented leadership (Cartwright \& Zander, 1960; DeRue, Nahrgang, Wellman, \& Humphrey, 2011; Hemphill \& Coons, 1957). Second, past research has focused mainly on the impact of leaders' personality on leadership emergence per se, whereas the present study explains the emergence and endorsement of taskand relationship-oriented leadership in terms of followers', as well as leaders' personalities. More specifically with respect to research on followership, it is only recently that researchers have recognized the role of followers' personalities in shaping perceptions of leadership, especially transformational leadership (e.g., see Felfe \& Schyn, 2010). Our study, however, was the first to link followers' big five personality traits to perceptions of task- and relationshiporiented leadership. Third, our design was longitudinal. To our knowledge, it was the first study to examine the impact of personality on emergent leadership and followership not only as it evolves over time, but across the entire life cycle of a group.

Our final and most important contribution was to go beyond standard individualistic approaches to leadership by adopting a relatively new social network approach to leadership that treated leadership as a shared (group) phenomenon. Specifically, shared leadership is defined "as an emergent team property that results from the distribution of leadership influence across multiple team members" (Carson, Tesluk, \& Marone, 2007, p. 1218), and argues for a more 
dynamic, interactive process of mutual adjustment and role occupation with respect to leadership within groups (Day et al., 2004). As such, this approach allows for the emergence of multiple leaders and more complex distributed leadership structures in groups (Carson et al., 2007; Mehra, Smith, Dixon \& Roberston, 2006). In the current study, we extend research on shared leadership by investigating how two distinct (task- and relationship-oriented) leadership roles can be shared among group members. Indeed, two informal leaders often emerge in leaderless groups - one to organize and structure tasks and the other to support and develop relationships (Bales, 1953; Burke et al., 2006; DeRue et al., 2011). In order to understand how task and relationship leadership are progressively distributed within groups over time, we applied a social network approach to leadership.

\section{Taking a social network approach to examining leaders and followers in groups}

Social network analysis is a sociometric procedure which maps and studies interpersonal relationships among people (actors) in a social group (Moreno, 1932; 1947). Such an approach is well-suited for studying leadership that is shared and emergent because it models patterns of relationships among interconnected individuals, it represents how leadership is distributed among group members, and identifies the emergence of multiple leaders (Carson et al., 2007; Mehra et al., 2006). Such leadership can be represented as a network of leadership perceptions (or "leadership network") where nodes and ties represent group members and leadership perceptions respectively. At the dyadic level, the direction of the tie distinguishes between the follower, who sends the tie (i.e., nominates a leader), and the leader, who receives the tie (i.e., is nominated as a leader). At the group level, emergent leaders are identified as the nodes receiving the greatest number of ties; followers by extension are those who send the greatest number of 
ties. A network representation therefore treats leadership as a group proc ess encompassing one or potentially several emergent leaders, and followers who recognize these leaders.

To explore the micro-personality dynamics that produce shared leadership at the group level of analysis (Thorpe, Gold, \& Lawler, 2011), in the present study we captured a selfmanaging group's task and relationship leadership networks at sequential points in time and model their evolution by using an advanced social network program, SIENA, developed to analyze panel network data (Snijders, 2009; Snijders, van de Bunt, \& Steglich, 2010). A longitudinal network approach statistically tests, in the same analysis, whether individuals scoring higher on specific personality traits are more likely to receive increasing numbers of leadership nominations (i.e., emergent leaders), send increasing numbers of leadership nominations (i.e., emergent followers), and determines the process by which leaders emerge by testing if followers tend to nominate individuals who are similar to themselves (in terms of personality) as a leader. Our approach is structural, in controlling for patterns of leader and follower nominations, and processual, in looking at who sends and receives increasing leader nominations over time (Fitzsimons, James, \& Denyer, 2011). Having briefly outlined the social network approach to leadership, we next derive specific predictions about personality and leaderfollower roles in the dynamic leadership network.

\section{Emergent leaders \& Big Five: Receivers in the leadership network}

A good starting point for any theoretical account of emergent leadership is leader categorization theory or implicit leadership theory (e.g. Lord \& Hall, 2003; Shondrick \& Lord, 2010). Lord and colleagues posit that leader categorization involves group members interacting and establishing a status structure by cognitively categorizing themselves and others based on 
social perceptions, typically inferences regarding personality traits and characteristics (Lord \& Hall, 2003). Both implicit leadership theories (ILTs) held by followers and implicit followership theories (IFTs) held by leaders are critical for shaping a stable leadership structure that emerges over time (Shondrick \& Lord, 2010).

In terms of the content of such leadership prototypes, there is considerable evidence showing that someone's personality plays an important role in judging whether that person is leader-like; that is, individuals who, by receiving more leadership nominations over time, become more "popular" (central) in a leadership network. For example, Judge et al. (2002) meta-analyzed 78 trait leadership studies and found that all of the Big Five factors except agreeableness were significantly related to leader emergence (whereas neuroticism was negatively related). More relevant to the present investigation, DeRue and his colleagues in their meta-analysis examined the link between personality and task- and relationship-oriented leadership style in established (i.e. formally designated) leaders (DeRue et al., 2011). For established leaders, conscientiousness was the strongest predictor of task-oriented leader effectiveness, and agreeableness and extraversion were the strongest predictors of relationshiporiented leader effectiveness.

In the current study we addressed recent calls in the literature for a more nuanced and developmental approach to the study of leadership by focusing on the emergence of task- and relationship-oriented leadership (DeRue et al., 2011). Guided by DeRue et al.'s (2011) metaanalytic findings we expected that conscientiousness, by virtue of its links to task completion, goal setting, and planning, would more likely predict the emergence of task- than relationshiporiented leadership. In contrast, we expected individuals high in agreeableness to be increasingly 
nominated as an interpersonally caring, friendship-based point of reference for the group over time, independent of any guiding structural direction of the group's task or project. In a similar vein, we anticipated that those high in extraversion would increasingly dominate the group in a sociable and outgoing manner, and thus be viewed as relationship-based leaders as opposed to task-based leaders.

In light of these previous findings on leaders' personalities, we hypothesized that openness to experience would be positively related to both task- and relationship-oriented leader emergence, while neuroticism would be negatively related to both styles of leadership emergence. We further anticipated that conscientiousness would be related to the emergence of task-based leadership, whereas both extraversion and agreeableness would be related to the emergence of relationship-based leadership.

Hypothesis 1a: Group members higher on openness to experience and lower on neuroticism will receive more nominations of task- and relationship-oriented leadership over time.

Hypothesis 1b: Group members higher on conscientiousness will receive more taskoriented leadership nominations over time.

Hypothesis 1c: Group members higher on extraversion and agreeableness will receive more relationship-oriented leadership nominations over time.

\section{Emergent followers \& Big Five: Senders in the leadership network}

Follower-centered approaches to leadership recognize the active role of followers in the leadership process (Meindl, 1995; Riggio, Chaleff, \& Lipman-Blumen, 2008; Schyns \& Felfe, 
2006) and suggest that followers' characteristics are just as important as a leaders' for sustaining the group as a whole (Felfe \& Schyns, 2010; Kaiser, Hogan, \& Craig, 2008). Moreover, in the context of a dynamic leadership network in which both the leadership and followership structure of the group (or network) naturally emerges over time, followers are likely to play an even more critical role in determining who leads and who follows.

There are compelling theoretical grounds for hypothesizing a link between individual's personality and their emergence as a follower. In a logical extension of leader categorization theory, Shondrick and Lord (2010) posit that people hold implicit beliefs about themselves and others as suitable followers (implicit followership theories; IFTs), with personality traits at the heart of these followership schemas. For example, a prototypical follower is generally regarded as hard-working, enthusiastic, and cooperative, whereas a non-prototypical follower is viewed as subversive, rejects authority, incompetent, and/or conforms too much and too easily (Sy, 2010). Follower characteristics are likely to be influential by guiding choices relating to leaders; whether they conform to them, resist them, or act as an audience (Collinson, 2006). Above and beyond these more general conceptions of followership, some researchers have shown that IFTs are also contingent on leader characteristics by showing the link between certain attributes of followers and certain kinds of leadership (Ehrhart \& Klein, 2001). For example, higher levels of followers' extraversion, agreeableness and emotional stability have been associated with greater recognition of transformational leadership in others (Felfe \& Schyns, 2010; Schyns \& Felfe, 2006). To date, however, no research has systematically investigated how followers' personality traits (as measured by the Big Five) affect their perceptions of which group members appear best-suited to enacting important task- and relationship-related leadership functions in the group, 
and how these preferences change over time in the context of real group interactions.

Nevertheless, this fundamental distinction between task- and relationship-based leadership has been prominent in theory and research on leadership behavior for over fifty ye ars (DeRue et al., 2011; Judge, Piccolo \& Ilies, 2004; Yukl, 2009). In the current study, by measuring the extent to which group members sent leadership ties to others in the network, it was possible to determine which group members emerged as followers over the life cycle of the group, the nature of those followers' personality, and the particular kind of leadership they endorsed in others (i.e. task versus relationship).

In terms of specific Big Five personality traits, agreeable individuals are regarded as altruistic, cooperative, modest, thoughtful, and considerate (McCrae \& Costa, 1987). Previous research suggests that agreeable followers may actually be quite passive, not actively identifying as many leaders in a group (e.g. Hetland, Sandal, \& Johnsen, 2008). Agreeable group members may therefore prefer to relate to other group members at a more interperso nal friendship level, and be relatively happy to let different would-be leaders take the risk of defining the group (Van Vugt, Hogan, \& Kaiser, 2008). Relatedly, but for different reasons, neuroticism is also likely to undermine the emergence of followership. Neuroticism is associated with emotional instability, lower self-esteem, higher anxiety, and heightened insecurity (McCrae \& Costa, 1987; Moss \& $\mathrm{Ngu}, 2006)$. As such, neuroticism generally interferes with healthy leader-member interaction via worrying about unpleasantness in relationships and emotional interference (Spangler, House, \& Palrecha, 2004). Furthermore, given that neuroticism is a risk factor for depression and can lead to general inactivity and disordered affective interactions (Duggan, Sham, Lee, Minne, \& Murray, 1995), we expected neurotic group members to be generally less assertive, decisive, or 
confident about potential leaders of either form. Thus, we anticipated that more agreeable and neurotic individuals would be less likely to play an active role in the emergence of either type of leadership in informal groups.

In contrast, we expected the remaining three personality factors to play a more active role in the emergence of followership. On one hand, conscientious individuals tend to be organized, responsible, and disciplined (McCrae \& Costa, 1987). Given that task leadership implies organizing and improving activities by providing structure, direction, reward/punishment, and the spanning of group boundaries (DeRue et al., 2011), conscientious individuals should be more likely to recognize and acknowledge task-related leadership behaviors in other group members (Ehrhart \& Klein, 2001; Roberts, Chernyshenko, Stark, \& Goldberg, 2005). Thus, conscientious followers are likely to be particularly receptive to displays of task leadership by others. However, we had no reason to expect that conscientiousness would be related to the endorsement of relationship-oriented leadership behavior in others. In contrast, extravers ion is a personality trait associated with sociability, talkativeness, high energy, dominance, and positive affect (McCrae \& Costa, 1987). Research generally indicates that people high on extraversion are more likely to seek interpersonal relations with others and more extraverted followers tend to es tablish closer relationships with their formal leaders (Philips \& Bedeian, 1994). Given that highly extraverted people are more attentive to positive social interactions, they may be more inclined to recognize and endorse relationship-oriented (but not task-oriented) leadership behaviors in other group members.

In a similar vein, prior research has shown that followers high on openness to experience show a preference for participatory leadership styles (Stevens \& Ash, 2001). Openness to 
experience reflects the degree to which individuals are curious, creative, driven to experience novelty, nonconformist, and accepting of diversity (e.g. McCrae \& Costa, 1987; Moss \& Ngu, 2006). As relationship-oriented leadership involves empowering, developing, inspiring, and encouraging participation amongst other group members (DeRue et al., 2011), followers more open to experiences may be more likely to recognize and endorse this kind of leadership displayed by other group members. Given that those higher in openness tend to be higher in divergent thinking and sensation seeking (Aluja, García, \& García, 2003; McCrae, 1987), they may not be particularly attentive to the coordination of group task structure, so we expected no relationship with perceptions of task leadership in others.

To summarize, it was expected that group members who were more agreeable and neurotic would send fewer nominations of task- and relationship-oriented leadership over time(i.e. they will be less likely to emerge as followers). In terms of those more likely to emerge as followers, it was predicted that those higher in extraversion and openness to experience would send more relationship leadership nominations, whereas those higher in conscientiousness would send more task leadership nominations over time.

Hypothesis 2a: Group members higher on agreeableness and neuroticism will send fewer nominations of task and relationship-oriented leadership over time.

Hypothesis 2b: Group members higher on extraversion and openness to experience will send more relationship-oriented leadership nominations over time.

Hypothesis 2c: Group members higher on conscientiousness will send more taskoriented leadership nominations over time. 


\section{Leader-follower similarity}

In addition to the personality of leaders who are most frequently nominated in the group and the personality of followers who are most likely to nominate particular leaders, the third and final component of leadership as an emergent group process is the interplay between leaders' and followers' personalities and the emergence of followership. More specifically, to what extent do followers nominate leaders with similar, as opposed to dissimilar, personality profiles?

The evidence regarding followers' preference for similarity versus complementarity of leader-follower personality is mixed. Furthermore, persuasive theoretical argu ments can be made for predicting either effect. On the one hand, both the similarity-attraction hypothesis and social identity theory (Hogg, 2001) posit that followers nominate leaders who they perceive to be similar to themselves because of enhanced likability, reduced dissonance, and the general selfesteem benefits of being able to more easily project and confirm positive aspects of one's own self-concept via a prototypical ingroup member (Ehrhart \& Klein, 2001; Felfe \& Schyns, 2010). Research in support of this argument found that personality similarity was positively related to better leader-member-exchange relationships (Bauer, Green, \& Bauer, 1996). Eagleson, Waldersee, and Simmons (2000) demonstrated that individuals are more likely to select those with a leadership style similar to their own as leaders for a management team. Furthermore, Felfe and Schyns (2010) found that perceptions of a similar leader personality mediated the relationship between follower personality and the recognition of transformational leadership.

On the other hand, there are also good reasons to expect that leaders and followers will prefer complementarity over similarity. Recent theories of leadership argue that social interactions include leaders and followers claiming, signaling and granting distinct identities as 
they mutually adopt differentiated roles over time, drawing attention to complementary

differences (DeRue \& Ashford, 2010). Thus individual differences can be used to meaningfully differentiate and provide self-esteem support between group members by satisfying a need for optimal distinctiveness (Brewer, 1991). Similarly, self-verification theory would suggest that group members with different leader- and follower-relevant personality characteristics will seek to enact corresponding leader-follower roles and appreciate it more if their differences are mutually acknowledged, confirming or verifying personal aspects of their self-concepts in a selfconsistent fashion (Riley \& Burke, 1995). Furthermore, leaders may be nominated precisely because they are different from the follower, and can therefore satisfy or fulfill a need for a particular quality that the follower is lacking (Ehrhart \& Klein, 2001).

In summary, given the ambiguity of the previous theoretical and empirical evidence, we made no predictions concerning the association between leader-follower (dis)similarity and the sending of both task- and relationship-oriented leadership nominations.

\section{METHOD}

\section{Sample}

The participants for this study were 41 undergraduate students involved in a three-month study abroad program ${ }^{1}$. There were 27 female and 14 male participants with ages ranging from 20 to $22(M=20.6$ years, $S D=0.5)$. The sample was homogeneous in terms of ethnic background (White North American). Only a few of the participants were friends before joining the program. All participants accepted to take part in our study, resulting in no missing data. 
The program combined classroom instruction with real-world projects, and required participants to travel extensively throughout Europe and live in the same accommodation for three months. Each month, participants were evaluated on their performance on specific classroom projects. Participants worked in groups (average 6 people per team) for each project (3 in total). Projects were designed to be challenging, involving data collection, analysis, presentation, and a final report. Performance on these group projects constituted a major part of their course work (counting for up to $100 \%$ of their grade). It is in the context of these classroom projects, where teams had to dedicate a significant amount of time and energy to reach their project's objectives, that task- and relationship-oriented leadership emerged: some individuals had to step up and exert a significant influence over their group to achieve their common goal (Northouse, 2007). For the purpose of our study, we collected network data at three separate points in time, one month apart. Each round of data collection corresponds to the end of a classroom project. Participants were asked to look back at their class-related experience and report on different types of social interactions.

\section{Measures}

Dependent Variables: Leadership Networks. To study leadership emergence in the informal group described above, we used a sociometric approach to capture how leadership may be shared among multiple leaders (Carson et al., 2007; Mehra et al., 2006; Moreno, 1932). Participants were provided with a definition of leadership and were then asked whom they perceived as a task-oriented leader (identified as individuals who provide "leadership when it comes to organization and planning") and relationship-oriented leader (identified as individuals who provide "leadership when it comes to making sure the group worked together as a team"). 
For each leadership type, respondents recorded their answer by placing a check by the names of each person they saw as a leader on a list containing all participants' names. Respondents were free to nominate as many leaders as they deemed appropriate. Respondents were given the possibility (but not instructed) to nominate the same leader as both a task and a relationship leader. Respondents were not explicitly given the possibility to nominate themselves as leaders. Answers were then coded in a binary matrix, where each cell Xij was coded as 1 if $\mathrm{i}$ reported $\mathrm{j}$ as a leader, 0 otherwise.

As leadership emergence is a dynamic phenomenon, we collected leadership networks at three points in time, one month apart. The same procedure was used for each round of data collection. By the end of our observation period, which coincides with the end of the study abroad program, we collected three adjacency matrices for each leadership style (task and relationship leadership). That is, our dependent variables are two changing leadership networks (one for task-based and the other for relationship-based) which capture how the overall pattern of leadership nominations change over time. By modeling the evolution of these two networks, we aim to understand how, and to which extent, attributes (personality) of the individual actors affect the dynamics of networks.

Individual Covariates (Independent Variables). The Big Five were measured using the Big Five Inventory (BFI - John \& Srivastava, 1999). The scale contains 44 self-descriptive items anchored at 1 (strongly disagree) and 5 (strongly agree). Summary scores were computed for each of the Big Five factors: extraversion, agreeableness, conscientiousness, neuroticism, and openness. As previous research consistently revealed that leadership emergence is positively related to 
cognitive intelligence (e.g. Taggar et al., 1999), we assessed participants' cognitive abilities. We used grade point average (GPA) as a proxy for cognitive abilities (Ridgell \& Lounsbury, 2004).

Advice \& Friendship Networks (Controls). The theory of relational leadership argues that leadership emerges from other social relationships among group members (Uhl-Bien, 2006). Fernandez (1991) as well as Mehra and colleagues (2009) have shown that leadership networks are influenced by friendship networks, specifically, people are more likely to nominate friends as leaders. To control for the influence of other types of social relationships on the evolution of leadership networks, we collected advice and friendship network data. As for the leadership networks, the advice network was assessed at three points in time, one month apart. Participants were asked "who did you ask for class advice this past month?" and, as for the leadership networks, recorded their answers by placing a check by the names of each person they went to for advice. Since only a few of the participants were friends before joining the program, the friendship network was collected at one point in time only, on the first day of the study abroad program. Participants were asked who they considered as friends.

\section{Modelling Approach}

The longitudinal leadership networks we collected cannot be analyzed using standard statistical procedures (e.g., regression) due to the high interdependence of network observations over time (Snijders et al., 2010). We therefore rely on a new class of models designed for social network panel data: stochastic actor-oriented models (SAOM) which are run using the program SIENA (Snijders, 2009; Snijders et al., 2010). For technical descriptions, we refer our reader to the work by Snijders and colleagues (2010). Simply stated, SAOM treat a dynamic network as a dependent variable (e.g., in this investigation, a longitudinal leadership network) and aim at 
investigating the many different tendencies driving its evolution. SAOM assume that changes in the network represent choices made by the actors in the network. In the context of this study, SAOM allow us to investigate the effect of the personality of actors on sending and receiving leadership nominations over time.

SAOM models simultaneously differentiate among "actor covariate effects" that are based on the characteristics or attributes of individual actors, "dyadic covariate effects" that are based on the characteristics of pairs of nodes, and "network effects" derived from the network structure (Snijders et al., 2010). In our analysis, network and dyadic effects are included as controls, while actor covariate effects model how the Big Five affect the evolution of the leadership network over the duration of the study abroad program.

Actor covariate effects test whether properties of actors explain the formation of leadership ties over time. Three types of effects can be modeled: sender, receiver, and similarity effects. Sender effects test if actors scoring higher on a particular covariate (e.g., openness) are more likely to send a greater number of ties over time (e.g., to nominate another individual as a leader). Sender effects will be used to test our hypotheses regarding emergent followership. Receiver effects capture the tendency for actors scoring higher on a particular covariate (e.g., conscientiousness or extraversion) to receive greater number of ties over time (e.g., to emerge as leaders). Receiver effects will be used to test our hypotheses regarding emergent leadership.

Finally, similarity effects associated with a covariate capture the tendency for individuals to send ties to others who are similar to themselves.

Dyadic covariates express the extent to which a tie between two actors is more likely when another social tie links both actors (Snijders et al., 2010). Simply stated, these effects allow 
us to control if a relationship (e.g., leadership) depends on the presence of another relationship (e.g., advice or friendship).

Network effects capture tendencies for the network to evolve around particular structures, or a pattern of ties. The literature suggests three network effects to be included, as controls, in our analysis: reciprocity, transitivity, and centrality. As leadership is expected to be an asymmetric and hierarchical relationship (Fernandez, 1991), ties within a leadership network are not likely to be reciprocated (Mehra et al., 2009): if Jay perceives Kyle as a leader, then Kyle will not perceive Jay as a leader. Transitivity, often seen as a measure for network closure "friends of my friends are my friends", can fulfill competitive motives in social relationships (Offstein, Madhavan, \& Gnyawali 2006). Transitivity in leadership relationships guides individuals into constructing a local hierarchy: if Mark perceives William as leader who perceives Joe as a leader, then Mark is more likely to perceive Joe as a leader. Finally, evidence on emergent leadership suggests a tendency toward high skewness in leadership choices (Mehra et al., 2006). It suggests that leadership networks will tend to become more centralized around "popular" actors. Specifically, emergent leaders will reinforce their social position and become nominated as leaders by a greater number of group members over time.

\section{RESULTS}

Table 1 reports the descriptive statistics (means, standard deviations, and, when applicable, reliability measures) as well as correlations on both the individual covariates and the dependent measures at each point in time. Descriptive network statistics suggest that the average number of relationship leaders decreases over time while the average number of task leadership nominations remains constant. Correlations over time between the number of ties sent and 
received for both types of leadership suggest that these are distinct constructs. Initially, group members largely nominated the same people as both task- and relationship-oriented leaders $(\mathrm{r}=.82, \mathrm{p}<.01$, at Time 1$)$, however, this tendency decreased over time $(\mathrm{r}=.61, \mathrm{p}<.01$, at Time 2). Indeed, by Time 3 group members ended up nominating different people as task- and relationship-based leaders (r=-.17, n.s.).

[Insert Table 1 about here]

For each type of leadership network, a set of SAOMs were built using a forward approach. Model 1 contains all control variables (network and dyadic covariates) as well as sender effects for all individual covariates. Model 2 adds receiver effects for all individual covariates. Finally, Model 3 adds similarity effects. Table 2 summarizes the models developed for assessing the evolution of the relationship-oriented leadership network while Table 3 shows the results for the task-oriented leadership network. We report each parameter's coefficient and significance. If a parameter equals zero, the corresponding effect plays no role in network evolution. If it is positive, it implies that "there will be a higher probability of moving in directions where the corresponding effect is higher, and the converse if the parameter is negative" (Snijders et al., 2010: 47). Using the forward approach, when describing our results, we report parameters from Model 3 only. Since Model 3 contains all controls and all effects of interest (sender, receiver, and similarity effects), it provides the most complex and integrative view of how the different effects impact the dynamics of the leadership networks.

[Insert Table 2 about here]

[Insert Table 3 about here] 
Emergent Leaders. To test if emergent leaders tended to be higher on specific personality traits, we must look at receiver effects for each Big Five trait. Our models revealed that group members higher on extraversion were more likely to receive task- and relationship-oriented leadership nominations over time (Table $2, \beta_{\text {extravert }}=.019, \mathrm{p}<.01$; Table $3, \beta_{\text {extravert }}=.020$, $\mathrm{p}<.01$ ). Our analysis also suggests that individuals who scored highly on openness were less likely to receive both types of leadership nominations (Table $2, \beta_{\text {open }}=-.022, \mathrm{p}<.05$; Table 3 , $\left.\beta_{\text {open }}=-.025, \mathrm{p}<.01\right)$. Neuroticism plays no significant effect on both types of leadership emergence. Taken together, these results provide only partial support for Hypothesis 1a. Group members higher on conscientiousness were more likely to receive more task-oriented leadership nominations over time (Table $\left.3, \beta_{\text {conscientious }}=.033, \mathrm{p}<.01\right)$, which supports Hypothesis $1 \mathrm{~b}$ Interestingly, we found that conscientiousness also facilitated the emergence of relationshipbased leaders (Table $\left.2, \beta_{\text {conscientious }}=.025, \mathrm{p}<.05\right)$. Finally, we found a marginally significant effect for Hypothesis 1c: group members higher on agreeableness received more relationshipbased leadership nominations over time (Table 2, $\left.\beta_{\text {agreeable }}=.025, \mathrm{p}<.10\right)$.

Emergent Followers. Sender effects shown in Tables 2 and 3 suggest that followers' personalities impact their propensity to send leadership nominations. In general, our models suggest the emergence of relationship-oriented leadership was significantly more affected by followers' personality than the emergence of task-oriented leadership. Results from Table 2 suggest that individuals who were more agreeable $\left(\beta_{\text {agreeable }}=-.026, \mathrm{p}<.01\right)$ and neurotic $\left(\beta_{\text {neurotic }}=-.022, \mathrm{p}<.05\right)$ than others sent less relationship-based leadership nominations; while individuals who were more open $\left(\beta_{\text {open }}=.023, \mathrm{p}<.05\right)$ were more likely to nominate others as relationship-oriented leaders. In contrast, individuals who were more conscientious were more 
likely to nominate task-based leaders (Table $3, \beta_{\text {conscientious }}=.028, \mathrm{p}<.05$ ). Thus hypotheses $2 \mathrm{c}$ and $2 \mathrm{~d}$ on conscientiousness and openness were supported, and hypotheses $2 \mathrm{a}$ and $2 \mathrm{e}$ on agreeableness and neuroticism were partially supported for relationship- (but not task-oriented) leadership. Given that extraversion showed no significant changes in ties sent over time, hypothesis $2 \mathrm{~b}$ was not supported.

Leader-follower (dis)similarities. Results in Table 3 suggest that followers tend to nominate as relationship-oriented leaders individuals similar to themselves only on openness to experience $\left(\beta_{\text {open }}=.496, \mathrm{p}<.05\right)$. In terms of leader-follower differences, results in Tables 2 and 3 demonstrate that leaders (both task- and relationship-oriented leaders) and associated followers tend to be dissimilar on agreeableness (Table 2, $\beta_{\text {agreeable }}=-.561, \mathrm{p}<.05$; Table $3, \beta_{\text {agreeable }}=$ $-.583, \mathrm{p}<.05)$. That is, a leadership tie was more likely to appear if a leader and follower were different on agreeableness.

\section{DISCUSSION}

Overall, our results generally supported our hypotheses, and confirmed that Big Five personality traits play specific and important roles in the emergence of shared leadership within a leaderless group. In terms of emergent leadership, individuals who were more extraverted, open to experience, and conscientious received more task- and relationship-oriented leader nominations as the network developed over time. In contrast, more agreeable individuals were marginally more likely to be nominated as relationship-oriented (but not task-oriented) leaders. With respect to emergent followership, group members who were more agreeable and neurotic were less likely to nominate relationship-based leaders, whereas those more open to experience were more likely to nominate relationship-oriented leaders. In addition highly conscientious 
group members were more likely to nominate task-oriented leaders. Both task- and relationshiporiented leader nominations were based on dissimilar levels of agreeableness between leaders and followers, while nominated relationship-based leaders tended to have similar levels of openness to experience to followers.

Our findings clearly link the Big Five personality traits to the emergence of task- and relationship-based leadership. Importantly, by identifying the personality profiles of group members who received more leadership nominations, we were able to refine our understanding of the role that personality plays in people's prototypes or implicit leadership theories (ILTs) of task- and relationship-based leaders (Shondrick \& Lord, 2010). Extraversion, openness to experience, and conscientiousness were positively related to receiving both task- and relationship-oriented leadership nominations. Although there was less differentiation between task and relationship leader functions than expected, there was some preliminary evidence that agreeableness is more important for relationship- than task-oriented leadership. Contrary to expectations, neuroticism played no significant role in leadership emergence. These results only partially replicate earlier meta-analytic findings (e.g., DeRue et al., 2011; Judge et al., 2002). The differences between our findings and previous research may be partly attributable to the different kinds of leadership measured (i.e., formal vs. emergent leaders) or the different kinds of research designs used. Our longitudinal social network design allowed for the emergence of multiple (i.e., shared) leadership across time. While previous research that has used cross-sectional perceptions of individual formal leaders has sometimes demonstrated the importance of agreeableness and neuroticism, our results appear to find these two traits less relevant to perceiving leaders dynamically, when emergent network nominations are used as measures of leadership. In 
contrast, our results show that extraversion, openness to experience, and conscientiousness all seem to be salient for both kinds of leadership functions (task and relationship). It is possible that these traits signify equally valued, influential group coordination skills in emergent leadership, therefore blurring the task-relationship leadership distinction. However, given that our results showed that it took three months for group members to clearly differentiate between task- and relationship-based leaders, it is possible that the differential impact of personality traits on taskversus relationship-based leadership is likely to be stronger over longer periods of time. Although plausible, this idea awaits further research. Future research should also aim to investigate whether personality traits are valued differentially in terms of various leadership behaviors emerging as appropriate for different situations, as argued by trait activation theory (e.g. De Hoogh, Den Hartog, \& Koopman, 2005).

Secondly, our findings link the Big Five to emergent followership. Overall, these findings have implications for identifying the specific cognitive content of the IFTs of leadership categorization theory. More specifically, our results shed light on which personality traits define followers most willing to send leadership ties and reciprocate leadership with followership (Shondrick \& Lord, 2010). As predicted, agreeableness and neuroticism were associated with reduced followership of relationship-oriented leaders over time. This is some what consistent with previous research linking agreeableness to passivity, laxity, and carelessly missed deadlines (Bettenhausen \& Murnighan, 1991; Hetland et al., 2008), and research linking neuroticism to worrying about conflict and unpleasant relationships, erratic affective reactions, and reduced perceptions of transformational leadership (Bolger \& Schilling, 1991; Felfe \& Schyns, 2006; Spangler et al., 2004). Future research should seek to further investigate the mechanisms 
underlying this phenomenon; in any case, it appears that neurotic and agreeable individuals are unreliable followers in relationship contexts, perhaps because they see this type of leaderfollower interaction as stressful, unnecessary, or do not recognize it as leadership per se.

As expected, those higher on openness were more likely to report following relationshiporiented leaders. Consistent with past research, followers who were open to experience were more likely to endorse leaders that were participatory in style and who focused on developing and empowering followers rather than the more formal structure and direction of the task (Aluja et al., 2003; Stevens \& Ash, 2001). Unexpectedly, extraversion did not play a role in the followership of either type of leader. In the current study it may have been that extraverted group members were too engaged with being leaders themselves, seeking attraction and status rather than bestowing leadership on others, and our network approach brought that tendency to the forefront by inviting explicit leadership nominations (Campbell, Simpson, Stewart, \& Manning, 2003). Given that virtually all previous research has made the more obvious connection between extraversion and leadership, future research may do well to investigate to what extent extraverts can follow at all, and under what conditions.

Group members higher on conscientiousness, as expected, were more likely to nominate and follow task-oriented leaders as the leadership networks emerged. In line with past research, conscientious followers are indeed geared to recognize and endorse task-related behaviors in leaders (Ehrhart \& Klein, 2001; Roberts et al., 2005), most likely because of their relative prioritization of group functions such as task execution and goal management (Gevers \& Peeters, 2009; Sy, 2010). 
Finally, we found partial support for the importance of leader-follower (dis)similarity. Both types of nominated leaders tended to be dissimilar in agreeableness from their corresponding followers. This complementarity effect is supported by the general theoretical stance held by optimal distinctiveness theory (Brewer, 1991), self-verification theory (Riley \& Burke, 1991; Swann \& Read, 1981), and leader-follower negotiation of distinctive roles (DeRue \& Ashford, 2010), where mutually accepting differences helps to support both the individual and the group. In contrast, relationship-oriented leaders and their followers tended to be similar in openness to experience, supporting theories of similarity-attraction and a shared social identity within a group (Ehrhart \& Klein, 2001; Hogg, 2001). Indeed, a baseline similarity in openness to experience may help a group to harness a diversity of emergent leaders and followers effectively (e.g. Homan et al., 2008). In our study, the relatively high size of the single group network may have made it hard for group members to finely distinguish personality diversity across many members. Future research should investigate how, when, and why personalities and emergent leader-follower roles fit together in groups based on similarities versus complementarities (e.g. Kristof-Brown, Barrick, \& Stevens, 2005).

\section{Limitations \& Future Research}

Despite gathering rich longitudinal network data, our study has several limitations. First, we focused on levels of actual similarity between the independent self-reports of group members' personalities rather than (within-person) levels of perceived similarity. Although, perceived similarity is clearly important and often has strong effects on follower preferences for leadership there are good reasons for examining actual similarity. For example, our focus on actual similarity circumvented the methodological problems associated with single source bias. 
Moreover, actual similarity tends to drive the effects of perceived similarity (e.g. Curry \& Kenny, 1974), so it enabled us to concentrate on a more distal, and rarely examined, cause of emergent leadership. In addition, the importance of actual similarity is supported by the notion that group members' interactions are sustained by having others see them consistently with how they see themselves, meaning that people's actual standing on a trait can be as important as their perceived standing on a trait (Swann \& Read, 1981).

Secondly, we relied on a relatively small student sample. To determine how far our findings generalize to other types of groups and larger populations requires further replications, although where reasonable comparisons could be made, our findings were generally consistent with previous research. Future research should therefore sample different group types where leadership, followership, and leader-follower characteristics may be different and operate differently (e.g. management groups, culturally diverse groups, friendship groups). Future research can also fruitfully incorporate corresponding tests of other individual differences, including empathy, narcissism, perspective taking, reciprocity norms, as well as leadership styles, and the various social constructions around leadership as a group process (DeRue \& Ashford, 2010).

Finally, the social network approach adopted in this study forces participants to nominate individuals within the group as leaders, which excludes the potential role of individuals outside the network (e.g., the professor, other students). Temporally, our approach looked at how the network emerged over a period of three months, in terms of ongoing nominations and ties as the network grew and established itself, but our analyses do not speak to precisely how immediate, stable, or long-lasting personality may influence the perceptions of leadership and followership. 
Our descriptive statistics provide some initial indication that individual personality traits may differentially affect leadership emergence over time. For example, while extraversion's impact on the emergence of relationship leaders grew stronger over time, agreeableness' initial impact diminished. In contrast, consciousness and extraversion had a constant impact on the emergence of task leaders over the three time periods. These subtleties were not directly reported in our SAOM as we did not hypothesize specific temporal dynamics due to a lack of prior research and these models, by default, analyze the overall evolution of the networks. However, it is hoped that future research could shed some light on these complex and interesting temporal issues.

\section{CONCLUSION}

Although leadership emergence is defined as a process during which some individuals are recognized as leaders by the group, somewhat surprisingly, the majority of research has focused on the study of leaders, not on the process of leadership emergence. In this study, we treated leadership emergence as a complex social process involving all group members and resulting in the emergence of multiple potential leaders (Mehra et al., 2006). To refine our understanding of this group process, we conducted a study on how group members' personalities influenced the emergence of task- and relationship-oriented leadership in the context of leaderless groups. By performing a longitudinal analysis of leadership networks using social network modeling, we conclude that emergent leadership is not ideally focused around a singularly exceptional individual. Instead, leadership is best viewed as a dynamic group process and that both leader and follower personality have an important part to play in the process of leader (and follower) emergence. .

\section{REFERENCES}


Aluja, A., García, O., \& García, L. F. (2003). Relationships among extraversion, openness to experience, and sensation seeking. Personality and Individual Differences, 35, 671-680.

Bales, R. F. (1953).The Equilibrium Problem in Small Groups. In T. Parsons, R.F. Bales, \& E.A. Shils (Eds) Working Papers in the Theory of Action. New York, NJ: Free Press.

Bauer, T. N., Green, S. G., \& Bauer, T. N. (1996). Development of leader-member exchange: A longitudinal test. Academy of Management Journal, 39, 1538-1567

Bettenhausen, K., \& Murnighan, J. K. (1991). The development of an intragroup norm and the effects of interpersonal and structural challenges. Administrative Science Quarterly, 36, 20-35.

Bolger, N., \& Schilling, E. A. (1991). Personality and the problems of everyday life: The role of neuroticism in exposure and reactivity to daily stressors. Journal of Personality, 59, 355386.

Bono, J. E., \& Judge, T. A. (2004). Personality and Transformational and Transactional Leadership: A Meta-Analysis. Journal of Applied Psychology, 89, 901-910.

Brewer, M. (1991). The social self: on being the same and different at the same time. Personality and Social Psychology Bulletin, 17, 475-482.

Burke C., Stagl, C., Klein, C., Goodwin, G., Salas, E., \& Halpin, S. (2006). What types of leadership behaviors are functional in teams? A meta-analysis. Leadership Quarterly, 17, $288-307$.

Campbell, L., Simpson, J., Stewart, M., \& Manning, J. (2003). Putting personality in social context: extraversion, emergent leadership, and the availability of rewards. Personality and Social Psychology Bulletin, 29, 1547-1559. 
Carson, J., Tesluk, P., \& Marrone, J. (2007). Shared leadership in teams: an investigation of antecedent conditions and performance. Academy of Management Journal, 50, 1217-1234.

Carsten, M., Uhl-Bein, M., West, B., Patera, J., \& Mcgregor, R. (2010). Exploring social constructions of followership: a qualitative study. Leadership Quarterly, 21, 543-562.

Cartwright, D., \& Zander, A. (1960). Group dynamics—research and theory. Evanston, IL:Row Peterson.

Collinson, D. (2006). Rethinking followership: a post-structuralist analysis of follower identities. The Leadership Quarterly, 17, 179-189.

Curry, T., \& Kenny, D. (1974). The effects of perceived and actual similarity in values and personality in process of interpersonal attraction. Quality and Quantity, 8, 29-44.

Day, D. V., Gronn, P., \& Salas, E. (2004). Leadership capacity in teams. Leadership Quarterly, $15,857-880$.

De Hoogh, A. H. B., Den Hartog, D. N., \& Koopman, P. L.(2005). Linking the Big Five-Factors of personality to charismatic and transactional leadership; perceived dynamic work environment as a moderator. Journal of Organizational Behavior, 26, 839-865.

DeRue, D. S., \& Ashford, S. (2010). Who will lead and who will follow? A social process of leadership identity construction in organizations. Academy of Management Review, 35, 627647.

DeRue, D. S., Nahrgang, J., Wellman, N., \& Humphrey, S. (2011). Trait and behavioral theories of leadership: An integration and meta-analytic test of their relative validity. Personnel Psychology, 64, 7-52. 
Duggan, C., Sham, P., Lee, A., Minne, C. \& Murray, R. (1995). Neuroticism: a vulnerability marker for depression evidence from a family study. Journal of Affective Disorders 35, 139143.

Eagleson, G., Waldersee, R., \& Simmons, R. (2000). Leadership behaviour similarity as a basis of selection into a management team. British Journal of Social Psychology, 39, 301-308.

Ehrhart, M., \& Klein, K. (2001). Predicting followers' preferences for charismatic leadership: the influence of follower values and personality. Leadership Quarterly, 12, 153-179.

Emery, C. (2012). Uncovering the role of emotional abilities in leadership emergence. A longitudinal analysis of leadership networks. Social Networks, In Press.

Felfe, J., \& Schyns, B. (2010). Followers' personality and the perception of transformational leadership: further evidence for the similarity hypothesis. British J ournal of Management, 21, $393-410$

Fernandez, R. M. (1991). Structural Bases of Leadership in Intraorganizational Networks. Social Psychology Quarterly, 54, 36-53.

Fitzsimons, D., James, K., \& Denyer, D. (2011). Alternative approaches for studying shared and Formatted: English (United Kingdom) distributed leadership. International Journal of Management Reviews, 13, 313-328.

Gevers, J., \& Peeters, M. (2009). A pleasure working together? The effects of dissimilarity in team member conscientiousness on team temporal processes and individual satisfaction. Journal of Organizational Behavior, 30, 379-400.

Hemphill, J. K., \& Coons, A. E. (1957). Development of the leader behavior description questionnaire. In R. M. Stogdill \& A. E. Coons (Eds.), Leader behavior: Its description and 
measurement (pp. 6-38). Columbus: The Ohio State University, Bureau of Business Research.

Hetland, H., Sandal, G. \& Johnsen, T. (2008). Followers' personality and leadership. Journal of Leadership \& Organization Studies, 14, 322-331.

Hogg, M. A. (2001). A social identity theory of leadership. Personality and Social Psychology Review, 5, 184-200.

Homan, A. C., Hollenbeck, J. R., Humphrey, S. E., Van Knippenberg, D., Ilgen, D. R., \& Van Kleef, G. A. (2008). Facing Differences With an Open Mind: Openness to Experience, Salience of Intragroup Differences, and Performance of Diverse Work Groups. Academy Of Management Journal, 51, 1204-1222.

Hurtz, G., \& Donovan, J. (2000). Personality and job performance: the Big Five revisited. Journal of Applied Psychology, 85, 869-879.

John, O. P., \& Srivastava, S. (1999). The Big Five trait taxonomy: History, measurement, and theoretical perspectives. In L. Pervin \& O.P. John (Eds.), Handbook of personality: Theory and research (pp. 102-138). New York, NJ: Guilford Press.

Judge, T.A, Bono, J., Ilies, R., \& Gerhardt, M. (2002). Personality and leadership: a qualitative and quantitative review. Journal of Applied Psychology, 87, 765-780.

Judge, T., Piccolo, R., \& Ilies, R. (2004). The forgotten ones? The validity of consideration and initiating structure in leadership research. Journal of Applied Psychology, 89, 36-51.

Judge, T.A, Piccolo, R. \& Kosalka, T. (2009). The bright and dark sides of leader traits: a review and theoretical extension of the leader trait paradigm. The Leadership Quarter ly, 20, 855- 
875.Kaiser, R., Hogan, R., \& Craig, S. B. (2008). Leadership and the fate of organizations. American Psychologist, 63, 96-110.

Kristof-Brown, A., Barrick, M. \& Stevens, C. (2005). When opposites attract: a multi-sample demonstration of complementary person-team fit on extraversion. Journal of Pers onality, 73, 935-958.

Lazarsfeld, P. F., \& Merton, R. K. (1954). Friendship as social process: A substantive and methodological analysis. In M. Berger et al. (Eds.), Freedom and Control in Modern Society (pp. 23-63). New York: Octagon.

Lord, R., \& Hall, R. (2003). Identity, leadership categorization, and leadership schema. In D. van Knippenberg, \& M. A. Hogg (Eds.), Leadership and power: Identity processes in groups and organizations (pp. 48-64). London: Sage.

McCrae, R. (1987). Creativity, divergent thinking and openness to experience. Journal of Personality and Social Psychology, 52, $1258-126$.

McCrae, R. \& Costa, P. (1987). Validation of the five-factor model of personality across instruments and observers. Journal of Personality and Social Psychology, 52, 81-90.

Mehra, A., Smith, B., Dixon, A., \& Robertson, B. (2006). Distributed leadership in teams: the network of leadership perceptions and team performance. Leadership Quarterly, 17, 232245.

Mehra, A., Marineau, J., Lopes, A. B., \& Kass, T. K. (2009). The Co-evolution of Friendship and Leadership Networks in Small Groups. In G., Graen \& J.A Graen (Eds.), LMX leadership: The Series, Vol. VII. Charlotte, NC: Information Age Publishing. 
Meindl, J. (1995). The romance of leadership as a follower-centric theory: a social constructionist approach. Leadership Quarterly, 6, 329-341.

Moreno, J. L. (1932). Application of the Group Method to Classification. New York, NJ: National Committee on Prisons and Prison Labor.

Moreno, J. L. (1947). Contributions of sociometry to research methodology in sociology. American Sociological Review, 12, 287-292.

Moss, S. A., \& Ngu, S. (2006). The relationship between personality and leadership preferences. Current Research in Social Psychology, 11, 1088-7423.

Northouse, G. (2007). Leadership theory and practice. (3rd ed.) Thousand Oak, London, New Delhe, Sage Publications, Inc.

Offstein, E. H., Madhavan, R., \& Gnyawali, D. R. (2006). Pushing the frontier of LMX research: The contribution of triads. In G. Graen \& J.A. Graen (Eds.), Sharing network leadership. Greenwich, CT: Information Age Publishing.

Pearce, C. L, Conger, J. A., \& Locke, E. A. (2007). Shared leadership theories. Leadership Quarterly, 18, 281-288.

Phillips, A. S., \& Bedeian, A. G. (1994). Leader-Follower Exchange Quality: The Role of Personal and Interpersonal Attributes. Academy of Management Journal, 37, 990-1001.

Ridgell, S. D., \& Lounsbury, J. W. (2004). Predicting academic success: General intelligence, "Big Five" personality traits, and work drive. College Student Journal, 38, 607-619.

Riggio, R. E., Chaleff, I., \& Lipman-Blumen, J. (2008). The art of followership. San Francisco: Jossey-Bass. 
Riley, A., \& Burke, P. (1995). Identities and self-verification in the small group. Social Psychology Quarterly, 58, 61-73.

Roberts, B., Chernyshenko, O., Stark, S., \& Goldberg, L. (2005). The structure of conscientiousness: An empirical investigation based on seven major personality questionnaires. Personnel Psychology 58,103-39.

Schyns, B., \& Felfe, J. (2006). The personality of followers and its effect on the perception of leadership: an overview, a study, and a research agenda. Small Group Research, 37, 522-539.

Shondrick, S. J., \& Lord, R. G. (2010). Implicit leadership and followership theories: Dynamic structures for leadership perceptions, memory, and leader follower proc esses. In G. P. Hodgkinson \& J. K. Ford (Eds.), International review of industrial and organizational psychology (vol. 25) (pp. 1-33). Chichester, England: John Wiley and Sons.

Snijders, T.A.B., (2009). Longitudinal methods of network analysis. In B. Meyers (Ed.), Encyclopaedia of Complexity and System Science (pp. 5998-6013). New York, NJ: Springer.

Snijders, T.A.B., van de Bunt, G.G., \& Steglich, C.E.G. (2010). Introduction to actor-based models for network dynamics. Social Networks, 32, 44-60.

Spangler, W., House, R., \& Palrecha, R. (2004). Personality and leadership. In B. Schneider \& D.B. Smith (Eds.), Personality and organizations (pp. 251-290). Mahwah, NJ: LawrenceErlbaum.

Stevens, C. D., \& Ash, R. A. (2001). Selecting employees for fit: Personality and preferred managerial style. Journal of Managerial Issues, 4, 500-517.

Swann, W. \& Read, S. (1981). Self-verification processes: How we sustain our self-conceptions. Journal of Experimental Social Psychology, 17, 351-372. 
Sy, T. (2010). What do you think of followers? Examining the content, structure, and consequences of implicit followership theories. Organizational Behavior and Human Decision Processes, 113, 73-84.

Taggar, S. (2002). Individual creativity and group ability to utilize individual creative resources: A multilevel model. Academy of Management Journal, 45, 315-330.

Taggar, S., Hackett, R., \& Saha, S. (1999). Leadership emergence in autonomous work teams: Antecedents and outcomes. Personnel Psychology, 52, 899-926

Thorpe, R., Gold, J. \& Lawler, J. (2011). Locating distributed leadership. International Journal of Management Reviews, 13, 239-250.

Uhl-Bien, M. (2006). Relational Leadership Theory: Exploring the social processes of leadership and organizing. Leadership Quarterly, 17, 654-676.

Van Kleef, G., Homan, A., Beersma, B., \& van Knippenberg, D. (2010). On angry leaders and agreeable followers: How leaders' emotions and followers' personalities shape motivation and team performance. Psychological Science, 21, 1827-1834.

Van Vugt, M., Hogan, R., \& Kaiser, R. (2008). Leadership, followership, and evolution: some lessons from the past. American Psychologist, 63, 182-196.

Yukl, G., (2009). Leadership in organizations. Englewood Cliffs, NJ: Prentice Hall. 
1 Another study (Emery, 2012) was also published from this sample. It is important to stress, however, that the present study differs from the Emery (2012) study in three fundamental ways. First, the independent variables in the two studies are distinct. Specifically, the Emery (2012) study focused on leaders' emotional ability, whereas the independent variables in the current study were leaders' and followers' big five personality traits. Second, the theoretical focus of the Emery study was on emergent leadership, whereas the theoretical focus of the present investigation was on emergent leadership, emergent followership and complementarity and similarity effects between leaders and followers. Hence, the current study addresses a broader and unique set of predictions compared to the Emery (2012) study. Finally, the social network analyses are different across the two studies: the SAOM modeling in the current study uses sender and similarity effects and includes a new dyadic covariate (an advice network). Therefore, to sum up, the theoretical framework, the predictions and the analyses are entirely independent across the two studies. 


\section{FIGURES}

Figure 1-Network effects

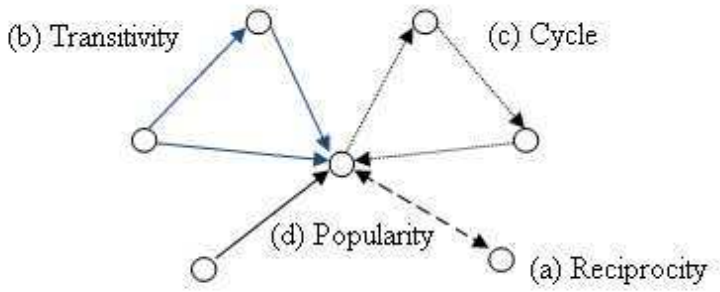




\section{TABLES}

Table 1 - Means, standard deviations, and correlations between the variables of interest

\begin{tabular}{|c|c|c|c|c|c|c|c|c|c|}
\hline & & Mean & $\mathrm{SD}$ & Range & $\begin{array}{c}\text { Cronbach } \\
\text { Alpha }\end{array}$ & 1 & 2 & 3 & 4 \\
\hline 1 & Agreeable & 37.9 & 4.4 & $27-45$ & .76 & & & & \\
\hline 2 & Conscientious & 32.5 & 4.4 & $24-40$ & .78 & .376 & & & \\
\hline 3 & Extravert & 29.1 & 7 & $14-40$ & .93 & -.012 & -.161 & & \\
\hline 4 & Open & 38.6 & 5.1 & $27-49$ & .76 & -.132 & .039 & .019 & \\
\hline 5 & Neurotic & 19.1 & 5.5 & $9-38$ & .83 & -.529 & -.021 & -.165 & .154 \\
\hline
\end{tabular}

Note: $\uparrow p<.10$ 
Table 2 - Evolution of Relationship Leadership Network

\begin{tabular}{|c|c|c|c|c|c|c|}
\hline \multirow[b]{2}{*}{ Network Effects } & \multicolumn{2}{|c|}{$\begin{array}{l}\text { Model } 1 \\
\text { coeff. }\end{array}$} & \multicolumn{2}{|c|}{$\begin{array}{l}\text { Model } 2 \\
\text { coeff. }\end{array}$} & \multicolumn{2}{|c|}{$\begin{array}{l}\text { Model } 3 \\
\text { coeff. }\end{array}$} \\
\hline & & & & & & \\
\hline Out-degree & -2.101 & $* *$ & -1.908 & $* *$ & -1.889 & $* *$ \\
\hline Reciprocity & 0.264 & & 0.344 & & 0.299 & \\
\hline Transitivity & 0.287 & $* *$ & 0.298 & $* *$ & 0.313 & $* *$ \\
\hline Cycles & -0.154 & & -0.091 & & -0.093 & \\
\hline Popularity & 0.239 & $* *$ & 0.198 & $*$ & 0.198 & $*$ \\
\hline \multicolumn{7}{|l|}{ Dyadic Covariates } \\
\hline Advice Class & 0.234 & & 0.216 & & 0.179 & \\
\hline Friends Time 0 & 0.086 & & 0.070 & & 0.089 & \\
\hline \multicolumn{7}{|l|}{$\begin{array}{l}\text { Individual Covariates } \\
\text { Sender Effects (Followers) }\end{array}$} \\
\hline GPA & -0.105 & & -0.060 & & -0.112 & \\
\hline Agreeable & -0.035 & $* *$ & -0.034 & $*$ & -0.035 & $* *$ \\
\hline Conscientious & 0.012 & & 0.004 & & 0.008 & \\
\hline Extravert & -0.013 & & -0.013 & & -0.012 & \\
\hline Open & 0.023 & $*$ & 0.027 & $* *$ & 0.022 & $*$ \\
\hline Neurotic & -0.023 & $*$ & -0.026 & $*$ & -0.023 & $*$ \\
\hline \multicolumn{7}{|l|}{$\begin{array}{l}\text { Individual Covariates } \\
\text { Receiver Effects (Leaders) }\end{array}$} \\
\hline GPA & & & -0.014 & & -0.001 & \\
\hline Agreeable & & & 0.027 & & 0.023 & \\
\hline Conscientious & & & 0.023 & $*$ & 0.024 & $*$ \\
\hline Extravert & & & 0.021 & $* *$ & 0.018 & $* *$ \\
\hline Open & & & -0.020 & $*$ & -0.021 & $*$ \\
\hline Neurotic & & & 0.022 & & 0.015 & \\
\hline \multicolumn{7}{|l|}{$\begin{array}{l}\text { Individual Covariates } \\
\text { Similarity Effects }\end{array}$} \\
\hline GPA & & & & & -0.266 & \\
\hline Agreeable & & & & & -0.553 & $*$ \\
\hline Conscientious & & & & & 0.099 & \\
\hline Extravert & & & & & -0.310 & \\
\hline Open & & & & & 0.489 & $*$ \\
\hline Neurotic & & & & & 0.268 & \\
\hline
\end{tabular}

$* * \mathrm{p}<0.01, * \mathrm{p}<0.05$ 
Note: Models were re-run adding sender, receiver, and similarity effects on "Gender". As none of the parameters on gender were significant, we concluded that, in this group, gender did not affect leadership emergence. 
Table 3 - Evolution of Task Leadership Network

Network Effects

Outdegree

Reciprocity

Transitivity

Cycles

Popularity

Dyadic Covariates

Advice Class

Friends Time 0

Individual Covariates

Sender Effects (Followers)

GPA

Agreeable

Conscientious

Extravert

Open

Neurotic

Individual Covariates

Receiver Effects (Leaders)

GPA

Agreeable

Conscientious

Extravert

Open

Neurotic

Individual Covariates

Similarity Effects

GPA

Agreeable

Conscientious

Extravert

Open

Neurotic

\begin{tabular}{cccccc}
$\begin{array}{c}\text { Model 1 } \\
\text { coeff. }\end{array}$ & \multicolumn{2}{c}{$\begin{array}{c}\text { Model 2 } \\
\text { coeff. }\end{array}$} & \multicolumn{2}{c}{$\begin{array}{c}\text { Model 3 } \\
\text { coeff. }\end{array}$} \\
\hline & & & & & \\
-1.893 & $* *$ & -1.886 & $* *$ & -1.896 & $* *$ \\
0.027 & & 0.016 & & 0.001 & \\
0.181 & $* *$ & 0.177 & $* *$ & 0.174 & $* *$ \\
-0.208 & $*$ & -0.209 & $* *$ & -0.209 & $*$ \\
0.068 & $* *$ & 0.059 & $* *$ & 0.061 & $* *$
\end{tabular}

$\begin{array}{lllll}0.313 & * * & 0.240 & * & 0.227 \\ 0.068 & & 0.090 & & 0.115\end{array}$

$\begin{array}{ccccc}-0.028 & & -0.022 & & -0.011 \\ -0.027 & * & -0.022 & & -0.016 \\ 0.028 & * * & 0.022 & * & 0.028 \\ 0.002 & & 0.004 & & 0.004 \\ -0.002 & & -0.005 & & -0.007 \\ -0.010 & & -0.010 & & -0.012\end{array}$

$0.150 * 0.152$ *

$-0.003-0.003$

$0.034 \quad * * \quad 0.033 \quad * *$

$0.019 \quad * * \quad 0.019 \quad * *$

$-0.021 * * \quad-0.025 \quad * *$

$0.000 \quad-0.003$

$-0.270$

$-0.579$

0.218

$-0.166$

0.301

0.220 
** $\mathrm{p}<0.01, * \mathrm{p}<0.05$ 